\title{
USE OF DRONES IN CROP PROTECTION
}

\author{
Bogusława BERNER, Jerzy CHOJNACKI \\ Mechanical Department, Koszalin University of Technology, POLAND \\ E-mail of corresponding author: bogusława.berner@tu.koszalin.pl
}

Keywords: management in precision agriculture, plant protection management, UAV, liquid spraying, crop protection

\begin{abstract}
Modern management in sustainable agriculture requires the fast information about condition of cultivated plants and the quick response to undesirable phenomena such as appearance of pests. The use of drones for spraying plants will allow for rapid application of plant protection agents on the growing areas. In this paper were presented results of research into the impact of rotors rotary speed of moving drone on the spray deposition on plant surfaces. The liquid was sprayed from the drone with the use of the XR 11002 flat fan nozzle at the pressure $0.2 \mathrm{MPa}$. The drone moved on a track with the permanent speed of $1.3 \mathrm{~m} \cdot \mathrm{s}^{-1}$. The liquid sprayed, which was water coloured with nigrosin, settled on foil testers that were secured on three levels (the upper leaf surface, the middle part of the plant, the level of soil under plants) in mustard plants. The height of the sprayer nozzle mounted on the drone over the plants was $0.6 \mathrm{~m}$. The tests were conducted at the zero speed of the rotors and at rotations of 1500 and 4000 revolutions $\cdot \mathrm{min}^{-1}$. The impact was found of the rotational speed of the drone rotors on the change of the distribution of liquid settling on the testers.
\end{abstract}

\section{INTRODUCTION}

The present constructions of drone, called also unmanned aerial vehicle (UAV), are divided into drones with electric drives, where electric batteries constitute the source of energy, and drones that are driven with the use of internal combustion engines. They are remotely controlled by the operator with the use of a transmitter or independently according to the programmed route. The use of unmanned aerial vehicles in agriculture can contribute to the efficient management of agricultural farms. They have already found applications in precision agriculture, where they are replacing planes and satellites in the remote sensing of crops (Pinter et al., 2003; Primicerio et al., 2012). Apart from the use of drones in activities that provide information in agriculture, they can also become part of agricultural machinery. At present, efforts are being undertaken to use them to perform spraying of crops with pesticides.

Due to their small range, which is mainly caused by the battery capacity, electric drones are chiefly used in operations on the small surfaces of fields situated on different heights or in locations that are hard to access (Berner \& Chojnacki 2017a). The advantages of the use of drones in the fight against pests include the possibility to quickly reach the place where the operation is to be performed and a short time of its performance; there are no problems connected with soil compaction or crumpling of plants. They can be particularly useful in the case of spot spraying over a large surface. Owing to replacing manual, backpack and tractor sprayers with them, the risk is reduced of poisoning of people who perform spraying with pesticides because the spraying drone operator is at a considerable distance from the place of the operation. The following are mentioned as the disadvantages of the use of drones to spray pesticides: a relatively high cost of the equipment as compared to possibilities offered by it, a small volume of the liquid tanks, a short flying time, the unreliability of the equipment and the uncertainty of the quality of operations (Sizhe et al., 2017). Because the operations with drones constitute an 
element of aerial application, the following pose additional problems: the risk of the liquid sprayed being carried away; the fact that the flights of unmanned airships are covered by aviation law.

Exchangeable pressure flat fan nozzles: narrowband and broadband are most frequently used to spray liquid (Giles \& Billing, 2015; Wei-Cai et al., 2016). Rotary atomizers can also be used (Huang et al., 2009). In the advanced designs of drones used in spraying, a computer with a GPS and a digital map of the field controls the operation of the spray gun (Huang et al., 2013). The flight of the drone is programmed taking into consideration the area covered by the operation.

The deposition of pesticides on plants with the use of unmanned aerial vehicles involves first of the combined effect of the jet of the liquid sprayed and the stream of air generated by the rotors, which must generate an air stream that is strong enough for the drone to fly at a specific height over plants and to move. A strong stream of air coming from the turning drone rotors is able to change the shape of the jet of the liquid sprayed. The research carried out into the impact of the stream of air generated by drone rotors on the distribution of the liquid that settles on the slot table demonstrates a possibility of an increased concentration of the liquid settled under the central part of the jet (Berner \& Chojnacki 2017b).

Attempts are taken to assess the impact of liquid spraying parameters, such as the working height and the operating speed of unmanned aerial vehicles on the settlement of drops on the plant. Tests are most frequently performed on plant crops. Water sensing papers placed on different heights in plant crops are used as the quality markers of the operations carried out. Research is also conducted related to biological effectiveness. The control of insects was studied on rice crop with the use of a drone (Wei-Cai et al. 2016). Tests of the effectiveness of spraying performed with the use of drones are also carried out in garden crops in relation to trees and shrubs (Giles \& Billing, 2015; Zhou \& He, 2016). The results obtained until now demonstrate that the area of testers covered with liquid and the density of drops that settle on them decreases with a rise of the drone flying speed (Zhou \& He, 2016). The research furthermore demonstrates that the quality of spraying performed with the use of drones in comparison with the quality of operations performed with the use of ground equipment may give similar results (Giles \& Billing, 2015). The research carried out until now has not provided an exhaustive answer as to the influence of essential factors on the quality of operations performed in relation to pesticides with the use of drones. As there is no fundamental knowledge on the quality of the operations performed of depositing pesticides, the organization of the field spraying process is not possible.

An assessment of the influence of air stream coming from the rotors of the spraying drone on the disposition of the liquid settled on plants was the purpose of the research.

\section{MATERIAL AND METHODS}

The test stand was built in a laboratory to avoid the impact of external conditions, particularly that of wind breezes, which may have an influence on the shape of the stream of drops and on carrying the drone off. The test stand is presented in Fig. 1.

The research was carried out with the use of a DJI S 900 drone: with six symmetrically positioned rotors. To ensure the repeatability and precision of the trajectory of the drone, it was secured to a horizontal cart moving along a frame with a track that was rigidly 
fixed to the ends on the stands. The cart was dragged with the use of an electric engine. Its rotations were controlled with the use of a current frequency converter. The drone was equipped with double propellers sized $15 \times 5,2 "$. Between the two rotors, in the connecting axis going through the middle of the rotors, a vertical bar was mounted symmetrically between the rotors. At the end of this bar, an XR 11002 flat fan nozzle manufactured by TeeJet company was mounted. The mouth of the spraying nozzle was below the bottom edges of the propellers of drone at the distance of $0.40 \mathrm{~m}$.

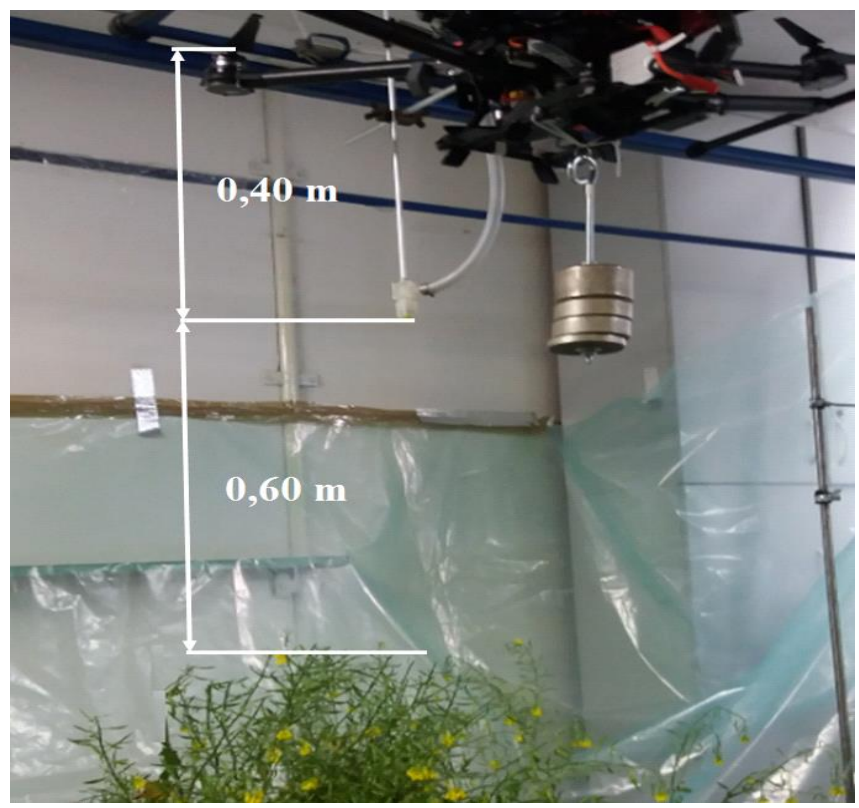

Fig. 1. View of test stand

Liquid to the spraying nozzle was delivery from a wheelbarrow sprayer. The pressure of the liquid before it accessed the nozzle was $0.2 \mathrm{MPa}$. Water mixed with water nigrosin constituted the liquid sprayed. The nigrosin concentration in the water was $0.38 \%$. No influence was assumed of the chemical composition of water and nigrosin on the size of drops generated by the spray gun (Parafiniuk et al. 2015). The research related to the settlement of the liquid was carried out on natural mustard plants that had been replanted from a field to boxes and placed under the drone. Testers were placed on the plants on three heights: the upper surface, the middle of the plant and on the ground level under the plant. The testers were mounted on handles fixed permanently to the plants in a such way that the place of the arrangement of the testers was not to be changed when repeating the experiments. The handles of the testers were under the symmetry centre of the nozzle, and they were moved in relation to one another by ca. $25 \mathrm{~cm}$. The testers were made from colourless polyethylene foil sized $37.2 \times 21 \mathrm{~mm}$. Each measurement was repeated three times. The height of the nozzle over the upper surface of the plants was $0.60 \mathrm{~m}$.

The rotational speed of the rotors over the flat fan nozzle was controlled with a DT-2259 optical tachometer fixed rigidly over one of the rotors. The drone with the cart moved along a track over the plant with a constant speed of $1.3 \mathrm{~m} \cdot \mathrm{s}^{-1}$ which corresponds to 4.7 $\mathrm{km} \cdot \mathrm{h}^{-1}$. The rotational speed of the drone rotors was set to: 0,1500 and 4000 revolutions $\cdot \mathrm{min}^{-1}$. The speed of " 0 " denoted the ride of the cart with the drone without any rotation of the rotors. A certain load was attached to the drone so that it could not ascend under the influence of the thrust coming from the rotors turning with a high speed. 
After it had dried, nigrosin from the testers covered with the liquid sprayed was washed off with distilled water, and the liquid was subjected to a photometric analysis: $5 \mathrm{ml}$ to establish the extinction of the dye. Based on conversion formulae, the concentration of nigrosin in the liquid was determined from the values of the extinction measurement; then, the volumes of the liquid that settled on the individual testers were determined.

\section{RESULTS AND DISCUSSION}

On the basis of the data obtained from the measurements, a diagram was prepared of the percentage distribution of the liquid settled on the individual levels of the plants according the following formula (Fig. 2):

$$
P_{i}=100 \cdot \frac{v_{i}}{\sum v_{i}}[\%]
$$

where:

$P_{i}$ - share of the volume of the liquid settled on the tester on i-th level in relation to the volume of the liquid settled on all levels, $\%$

$v i$ - volume of the liquid settled on the testers on i-th level.

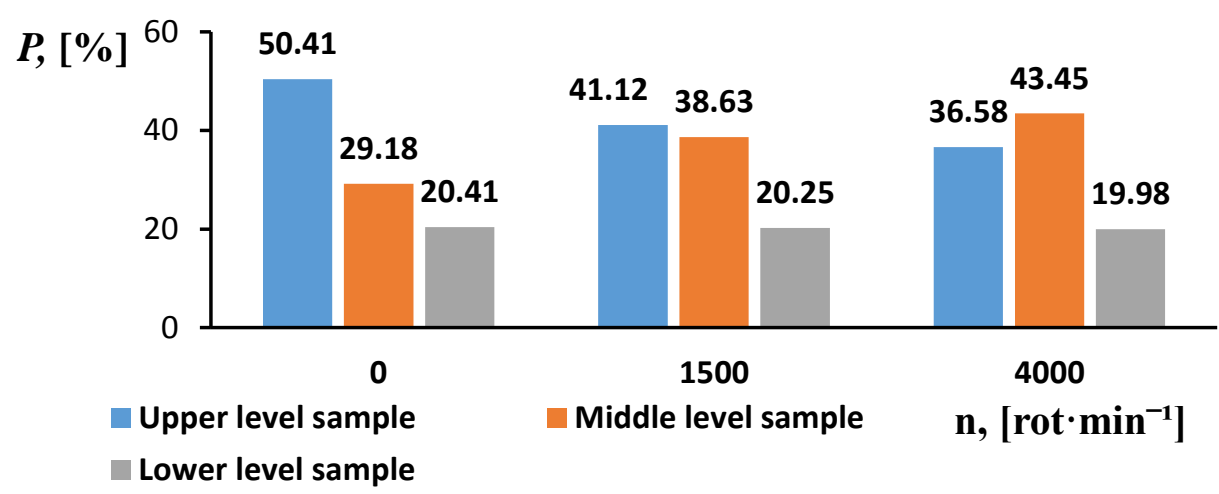

Fig. 2. Covering of testers with liquid depending on the rotation speed of drone rotors

A diagram of the coefficient of variation, as an inequality distribution index: $\mathrm{CV}$, was performed for the liquid settled on the testers in relation to the speed of the rotors with propellers according to formula 2 (Fig. 3). There also was counted the average volume of the liquid settled on all testers at a given rotational speed of the propellers: $V p$ - presented in Fig. 4.

$$
C V=\frac{100}{v_{s r}} \sqrt{\frac{\sum\left(v_{i}-v_{s r}\right)^{2}}{3}}[\%]
$$

where:

$C V$ - the inequality distribution index of the settlement of the liquid on the testers, \%, $v_{s r}$ - average volume of the liquid settled on the testers determined for testers from three level. 


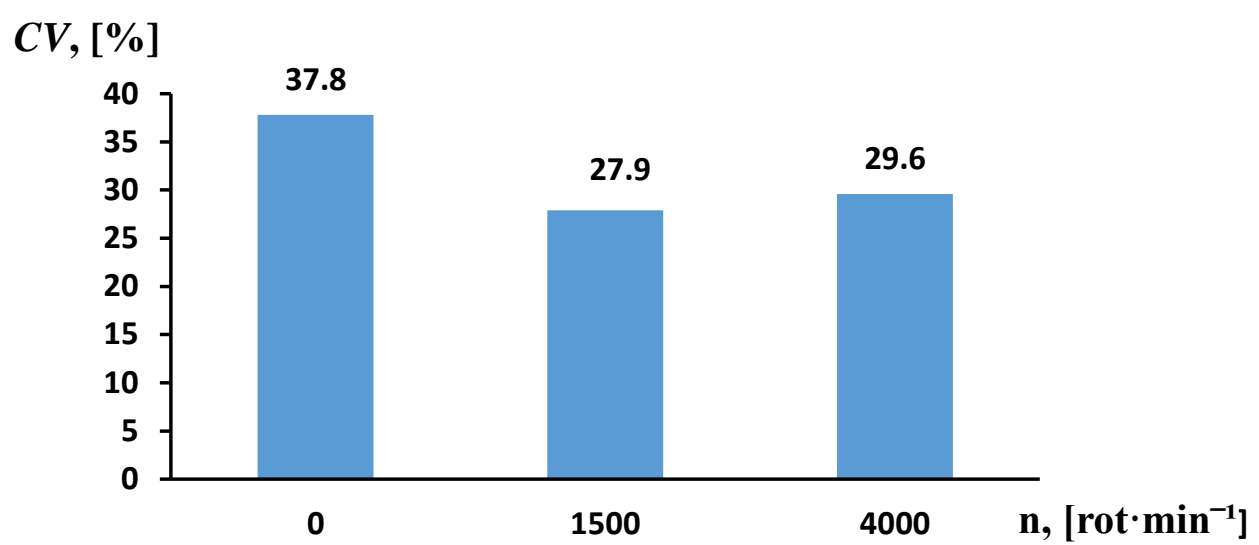

Fig. 3. Impact of the rotational speed of rotors on the inequality index CV of liquid that settled on testers

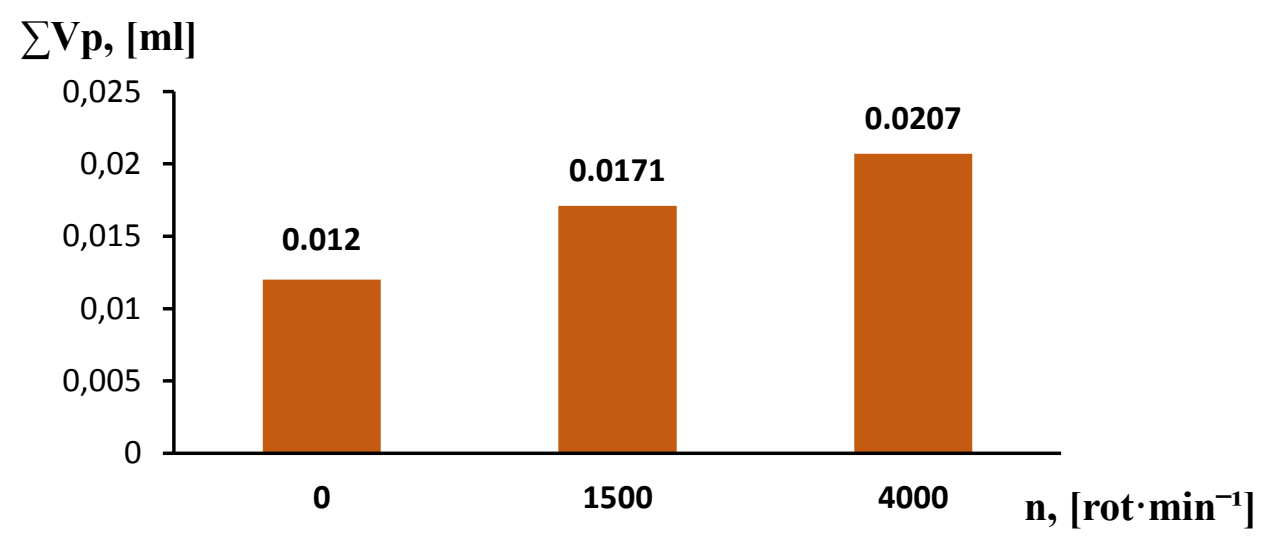

Fig. 4. Average volume of the liquid settled on the testers depending on the rotation speed of drone rotors

It can be observed from the diagram presented in figure 2 that the percentage share of covering the upper testers placed on the plant with the working liquid fell with a rise of the rotational speed of the drone rotors. The share of the liquid settled on the testers on the average level of the plants increased. No change to the share of the liquid settled on the bottom testers was observed.

It is evident based on the diagram in figure 3 that an increase of the speed of the drone rotors reduces the inequality index of the distribution of the liquid on the testers. It may be concluded that it is the effect of the increasing speed of the air stream, which blew the liquid sprayed into the inside of the plants. The average volume of the liquid settled on all the testers for a given rotational speed of the rotors increased with the rotations of the drone rotors. The testers were under the axle of the symmetry of the spray gun. This is the result of a change in the shape of the liquid jet and the thickening of the drops in the central part of jet under the influence of the air stream (Berner \& Chojnacki 2017b).

\section{CONCLUSIONS}

The rush of air from the drone rotors, where the liquid is sprayed from, may change the concentration of drops in the air stream causing their greater concentration in relation to the area which the drops fall on. An increase of the average volume of the liquid settled on the testers may be an effect of this phenomenon. 
The rotational speed of the drone rotors that performs spraying of the plants has an influence on the volume of the drops settled on the different levels of the plants. The stream of air coming from the drone rotors can cause a penetration of the stream of drops into the internal structure of the plants. The greater the rotational speed of the rotors is, the lower location is of water deposited on the plants. As a result of this, the rush of air may change the inequality index of the volume of the liquid settled on the different levels of the plants. The tank with the liquid sprayed mounted on the drone which gradually becomes empty during the operation will cause a change in the load of the drone. This will be the reason of a reduction of the rotational speed of the drone rotors. Its controlling system will be trying to maintain the required flying height. This means that during spraying the air stream which is required to create the appropriate lifting force of the drone may cause a change to the sedimentation of the liquid on the surface of the plants and its penetration into the deeper levels of the plants.

The knowledge obtained will offer an opportunity to plan plant protection operations with the use of drones. When preparing the technological process of pesticide applications by means of unmanned aerial vehicles should be considered that conditions of UAV using may be different than typical sprayers.

\section{REFERENCES}

Berner B., Chojnacki J. (2017a) Zastosowanie bezzałogowych statków powietrznych do opryskiwania upraw rolniczych. Technika Rolnicza Ogrodnicza Leśna, 2, 23-25.

Berner B., Chojnacki J. (2017b) Influence of the air stream produced by the drone on the sedimentation of the liquid sprayed that contains entomopathogenic nematodes. Journal of Research and Applications in Agricultural Engineering, 3,

Giles D. K., Billing R. C. (2015) Deployment and Performance of a UAV for Crop Spraying. Chemical Engineering Transactions, 44.

Huang Y., Hoffmann W.C., Lan Y., Wu W., Fritz B. K., Thomson S. J. (2009) Development of a Spray System for an Unmanned Aerial Vehicle Platform. Applied Engineering in Agriculture, 25(6), 803-809.

Huang Y., J. Thomson S., W. Hoffmann, C. Lan Y., K.: Fritz B. (2013), Development and prospect of unmanned aerial vehicle technologies for agricultural production management. International Journal of Agricultural and Biological Engineering, 6, 3, 1-10

Parafiniuk S., Marek Milanowski M., Subr A. K. (2015), The influence of the water quality on the droplet spectrum produced by agricultural nozzles. Farm Machinery and Processes Management in Sustainable Agriculture, 7th International Scientific Symposium, Agriculture and Agricultural Science Procedia, 7 , $203-208$

Pinter, P., Hatfield, J., Schepers, J., Barnes, E., Moran, M., Daughtry, C., Upchurch, D. (2003), Remote sensing for crop manage-ment. Photogramm. Eng. Remote Sens., 69, 647-664.

Primicerio J., Di Gennaro S. F., Fiorillo E., Genesio L., Lugato E., Matese A. Vaccari F. P. (2012), A flexible unmanned aerial vehicle for precision agriculture. Precision Agric, 13, 517-523.

Sizhe Z., Jie M. Wenshen J., Hengzhi Z. (2017) Development Prospect of the Plant Protection UAV in China. ASABE Annual International Meeting, 16-19.

Wei-Cai Q., Bai-Jing Q., Xin-Yu X., Chen Ch. , Zhu-Feng X.,Qing-Qing Z. (2016), Droplet deposition and control effect of insecticides sprayed with an unmanned aerial vehicle against plant hoppers. Crop Protection 85, 79-88.

Zhou L. P., He Y. (2016) Simulation and optimization of multi spray factors in UAV. ASABE Annual International Meeting, 17-20 